\title{
Toxicity of selenium, application of selenium in fertilizers, selenium treatment of seeds, and selenium in edible parts of plants
}

\author{
F. Garousi \\ e-mail: farzaneh@agr.unideb.hu \\ University of Debrecen, Faculty of Agricultural and Food Sciences and \\ Environmental Management, Institute of Food Technology, \\ HU-4032 Debrecen, Böszörményi út 138., Hungary
}

\begin{abstract}
Agronomic biofortification is one of the approaches which have been successfully adopted for improving the nutritional content of plant-based foods and is mainly focused on optimizing the application of mineral fertilizers and/or the improvement of the solubilization and mobilization of mineral elements in the soil. In general, mineral elements with a good dynamism in the soil and in the plant are good candidates for a prosperous agronomic biofortification. Selenium deficiency occurs in areas where soil Se is low, including parts of Europe, China, North America, Australia, New Zealand, and Southern Africa. Selenium toxicity occurs in areas where soil Se is naturally high, including areas of China, India, and the United States. Toxicity from naturally occurring Se may be intensified by irrigation of seleniferous soils, mining, and use of Se-rich fossil fuels. Then, management practices benefit from a thorough understanding of the mechanisms of plant Se uptake and the fate of Se in different plant species.
\end{abstract}

Keywords and phrases: selenium, toxicity of selenium, selenium-sulphur interrelation, selenium in plants, selenium in fertilizers 


\section{Toxicity of selenium and its tolerance in plants}

Accumulation of Se in the tissues of plants lead to symptoms of toxicity, such as stunting, chlorosis, and fading of leaves, between $2 \mathrm{mg} \mathrm{kg}^{-1}$ in nonaccumulators, such as rice, and $330 \mathrm{mg} \mathrm{kg}^{-1}$ in white clover (Mikkelsen et al., 1989), to several thousands of $\mathrm{mg} \mathrm{kg}^{-1}$ in the accumulator Astragalus bisulcatus (Shrift, 1969). There are some factors that help identify the susceptibility of a certain plant to toxicity, such as Se concentrations, levels of sulphate in the soil, the stage of growth, and the chemical form of the concentrated Se. It has been observed that both selenite $\left(\mathrm{SeO}_{3}^{2-}\right)$ and selenate $\left(\mathrm{SeO}_{4}^{2-}\right)$ are major forms of toxic to non-accumulators because they are readily absorbed and assimilated by plants ( $W u$ et al., 1988).

The interpolation of seleno-amino acids, selenocysteine, and selenomethionine into proteins instead of cysteine and methionine and then the changes in the tertiary structure, resulting from differences in size and ionization properties between S and Se atoms, may have a negative effect on the catalytic activity of certain important proteins and may induce the major mechanism of Se toxicity (Brown \& Shrift, 1982). It has also been found that Se induces toxicity in plants by interfering with chlorophyll combination (Padmaja et al., 1989) as well as with nitrate accumulation (Aslam et al., 1990). There is also proof that Se can interfere with the production of glutathione, and thus decrease a plant's defence against hydroxyl radicals and oxidative stress (Bosma et al., 1991). It appears that there is a high tolerance of accumulators regarding Se levels that would result in toxicity in non-accumulators because of the decrease of intracellular concentrations of selenocysteine and selenomethionine, hence preventing their interpolation into proteins. This is brought about by turning the Se into non-protein seleno-amino acids, such as selenocystathionine, or into the dipeptide $\gamma$-glutamyl-seleno-methyl-selenocysteine (Nigam et al., 1969). There is some proof that this may, to some amount, be achieved by the compartmentation of the element in the form of selenate or, maybe, as non-protein seleno-amino acids, in vacuoles (Terry et al., 2000), as suggested by Reilly (2006).

It has been reported that toxic Se concentrations in non-accumulator plants result in a 10\% decrease of yield, without any visible symptoms (Se contents between of 2 and $330 \mathrm{mg} \mathrm{kg}^{-1}$ in rice and white clover resp.). In accumulator plants, Se concentration may reach $4,000 \mathrm{mg} \mathrm{kg}^{-1}$, without any negative effects (Kabata-Pendias, 2011). Tolerance mechanisms include processes of exclusion of active Se amino acids, thus preventing their incorporation into proteins and the damaging effects on plant functions (Terry et al., 2000). The deprivation 
of Se from proteins in accumulator plants is the basis for their tolerance to Se. Generally, food crops have a low Se tolerance; however, most other plants may accumulate amounts of Se that are toxic for humans and animals. In nontolerant plant species, a surplus of Se may destroy germination and growth and cause chlorosis and black spots on leaves. Increased Se levels in plants repress their concentrations of $\mathrm{N}, \mathrm{P}$, and $\mathrm{S}$, just as different amino acids do; thus, high Se concentrations inhibit the absorption of metals, mainly $\mathrm{Mn}, \mathrm{Zn}, \mathrm{Cu}$, and $\mathrm{Cd}$. These connections are dependent on the ratio between the elements, and therefore it is possible for high Se levels to have stimulating effects on the uptake of some trace elements. The application of N, P, and S is known to help in detoxifying Se, which is perhaps a result either of suppressing Se uptake by the roots or of establishing a beneficial ratio of Se with these elements, as suggested by Kabata-Pendias (2011).

It has been reported that when Se-sensitive plants are subjected to high levels of Se in the soil-root medium, they may show various symptoms such as short growth, chlorosis, withering, drying of leaves, and premature death of the entire plant (Mikkelsen et al., 1989). In general, the threshold range in non-accumulator plants varies with plant age and S supply as younger plants can be more sensitive to toxicity, while tolerance to Se toxicity reaches higher levels with increasing sulphate supply (Brown and Shrift, 1982). The threshold toxic content in non-accumulator plants also depends on the form of Se applied and with selenate and selenite being the major toxic forms for plants. This may be linked to both these forms of Se readily absorbed and translocated in plants and assimilated in the inorganic forms (de Filippis, 2010).

We can conclude a number of possible modes of tolerance to toxic compounds, which are described by Pilon-Smits (2005) and may involve any of the six mechanisms - these include differences in adsorption, conjugation, sequestration, enzymatic modification, enzymatic degradation, and volatilization. Tolerance in Se-accumulator plants is apparently due to a number of mechanisms such as: 1) Adsorption or transportation: decrease in excessively high concentrations of Se being transported into the cells of leaves. 2) Sequestration or enzymatic modification: accumulation of Se in seleno-amino acids, but these seleno-amino acids are not incorporated into normal protein synthesis. 3) Sequestration: compartmentation of Se as selenate in the vacuole and away from more sensitive cytoplasmic reactions. 4) Enzymatic modification: increase ATP sulphurylase and SeCys methyltransferase activities to decrease inorganic Se to organic forms of Se, although other enzymes and reactions are also required. 5) Conjugation: conjugation with glutathione (GSH) and an increase in antioxidation protective reactions. Conjugation with Se-binding 
proteins and polypeptides decreases inorganic Se content. 6) Volatilization: increase volatilization of mainly organic forms of Se out of plant cells and tissues (de Filippis, 2010).

It is a well-known fact that plant species vary in their ability to accumulate Se and most plants have less than $25 \mathrm{mg} \mathrm{Se} \mathrm{kg}^{-1}$ dry matter and are called nonaccumulators. Such plants are unable of tolerate high Se in the surrounding,

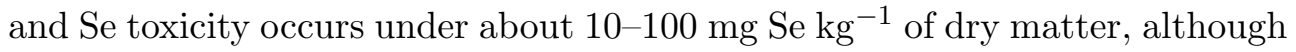
the exact value depends upon the selenate:sulphate ratio in the rhizosphere solution (White et al., 2004). These plants tolerate low Se concentrations in the rhizosphere by limiting Se uptake and movement to the shoot ( Wu et al., 1988). Different plant species can grow sufficiently in both seliniferous and non-seliniferous soils, and they may contain more than 1,000 mg $\mathrm{Se} \mathrm{kg}^{-1}$ dry matter without consequence (White et al., 2004).

Therefore, we may conclude that both selenite $\left(\mathrm{SeO}_{3}^{2-}\right)$ and selenate $\left(\mathrm{SeO}_{4}^{2-}\right)$ are main forms that are toxic to non-accumulators because they are readily absorbed and assimilated by plants (Domokos-Szabolcsy et al., 2011). Additional Se levels in plants repress their concentrations of N, P, and S, like different amino acids, thus high Se concentrations prevent the absorption of metals, originally $\mathrm{Mn}, \mathrm{Zn}, \mathrm{Cu}$, and $\mathrm{Cd}$. These communications are dependent on the ratio between the elements. The application of $\mathrm{N}, \mathrm{P}$, and $\mathrm{S}$ is believed to help in detoxifying Se, which is perhaps a result either of suppressing Se uptake by the roots or of establishing a beneficial ratio of Se with these elements.

\section{Selenium-sulphur interrelation}

$\mathrm{S}$ and Se have received little attention so far with respect to biotechnologybased crop improvement, at least when compared with nitrogen or phosphorus. In pursuit of a higher yield, better nutritional value, and quality in combination with sustainable plant management, various biotechnological approaches have tried to modify crop plants in recent years (Khan \& Hell, 2008). Plant nutritional aspects may be the major reason for this lack of interest of $\mathrm{S}$ and Se. Moreover, $\mathrm{S}$ is the least necessary one among the six macronutrients and is usually available in sufficient amounts in soils of arable land. Its mineral fertilization is relatively affordable, often combined with chemically decreased nitrogen (ammonium sulphate), and even $\mathrm{S}$ contaminations of nitrogen and phosphate mineral fertilizers may be sufficient to support crop growth in some cases (Pasricha \& Abrol, 2003). On the other hand, Se still has not been pointed out as a necessary nutrient for plants (not regarding algae), and it 
just plays the role of a potentially deleterious component in small agricultural areas with great selenate content in the soil. However, many decreased Se compounds, such as methionine and different vitamins (Hell, 1997), are necessary in the human diet as is selenide in a steadily increasing number of specialized enzymatic actions (Sors et al., 2005b).

The close relationship between Se and S metabolism in plants may be due to the physical and chemical similarities of Se and S. Both S and Se are part of Group 16 in the periodic table, the most common valence states of $\mathrm{S}$ and $\mathrm{Se}$ being $-2,0,+2,+4,+6$, with Se occurring as $\mathrm{Se}^{2-}$ (selenite), Se0 (elemental selenium), $\mathrm{Se}_{2} \mathrm{O}_{3}^{2-}$ (thioselenate), $\mathrm{SeO}_{3}^{2-}$ (selenite), and $\mathrm{SeO}_{4}^{2-}$ (selenate) respectively. The predominant forms of $\mathrm{S}$ and Se available for plants are $\mathrm{SO}_{4}^{2-}$, $\mathrm{SeO}_{4}^{2-}$, and $\mathrm{SeO}_{3}^{2-}$ (Sors et al., 2005a). These elements have some chemical differences, from which one can infer that some biochemical activities including Se are perhaps excluded from those associated with S. As observed from the periodic table, the Se atom is larger than $\mathrm{S}$ with a radius of $0.5 \AA \mathrm{com}$ pared to $0.37 \AA$, for S. Consequently, the bond between two Se atoms is almost one-seventh longer and one-fifth weaker than the disulphide bond (Sors et al, 2005b). $\mathrm{SO}_{4}^{2-}$ and $\mathrm{SeO}_{4}^{2-}$ competed for influx to plant roots (Shennan et al., 1990), and exhibited similar Michaelis constants (Km) for high-affinity transport $\left(\mathrm{K}_{m}=15-20 \mu \mathrm{M}\right)$, which was historically observed. However, when plants are supplied with mixtures of $\mathrm{SO}_{4}^{2-}$ and $\mathrm{Se}_{4}^{2-}$, the $\mathrm{Se} / \mathrm{S}$ concentration ratio in shoot tissues is rarely identical to the $\mathrm{Se} / \mathrm{S}$ concentration ratio in the rhizosphere (White et al., 2004). In fact, there is often no correlation between the shoot Se and S concentrations of various plant species (or even ecotypes of the same species) growing in the same environment (Feist and Parker, 2001), although strong relationships between shoot Se and $\mathrm{S}$ concentrations have been announced when the analysis was limited to Se non-accumulator crop plants (Hurd-Karrer, 1937), as pointed out by White et al. (2007).

The Se:S accumulation ratio is obtained by S supply, suggesting that the sulphate transporters induced by $\mathrm{S}$ deficiency are more selective for $\mathrm{SO}_{4}^{2-}$ than the sulphate transporters present. Taken together, these observations suggest that several sulphate transporters, with contrasting anionic selectivities, facilitate the uptake of $\mathrm{SO}_{4}^{2-}$ and $\mathrm{SeO}_{4}^{2-}$ by plant roots and that the complementation of these is determined genetically and may be regulated by the plant's nutritional situation. However, the structural basis of the anionic selectivity of different sulphate transporters is unknown. Following uptake by root cells, $\mathrm{S}$ and $\mathrm{Se}$ are converted into $\mathrm{SO}_{4}^{2-}$ and $\mathrm{SeO}_{4}^{2-}$, which are then loaded into the xylem and transported to the shoot, where they are assimilated into organic composites. Most $\mathrm{SO}_{4}^{2-}$ assimilations take place in the shoot, and the enzymes 
responsible are generally encoded by wide gene families, whose products are directed to various intracellular compartments (Hawkesford, 2005).

An enhancement in the expression of genes encoding these enzymes is generally observed during S starvation (White et al., 2007). Selenate is accumulated in plant cells against an electrochemical potential (or gradient) by active transport driven by ATP (ATPase). $\mathrm{SeO}_{4}^{2-}$ readily competes with the uptake of $\mathrm{SO}_{4}^{2-}$, and both anions become clear to be taken up by a number of sulphate transporters in the root plasma velum (Abrams et al., 1990). The sulphate transporters modulate Se uptake in bacteria and yeasts, and at least two kinds of these transporters are also present in plants.

The characterized S/Se transporters belong to two major classes (de Filippis, 2010): 1) Transporters that have high affinity for sulphate (HAST), which is likely to be the primary transporter involved in the sulphate uptake from the soil, and it is expressed mainly in roots with a $\mathrm{Km}$ for sulphate of $7-10 \mu \mathrm{M}$. HAST is also considered to be involved in selenate uptake; and 2) Transporters with a low affinity for sulphate (LAST), which secondary transporter is more likely to be included in the intercellular transport of sulphate, expressed in both the roots and shoots with a $\mathrm{Km}$ for sulphate of $100 \mu \mathrm{M}$. LAST is also regarded to be involved in selenate uptake (Cherest et al., 1997). Hence, we may conclude that the physical and chemical similarities of Se and S help to describe the close relationship between Se and $\mathrm{S}$ metabolism in plants. Both $\mathrm{S}$ and Se are part of Group 16 in the periodic chart; the Se atom is larger than $\mathrm{S}$ with a radius of $0.5 \AA$ compared to $0.37 \AA$ for $\mathrm{S}$. Several sulphate transporters, with contrasting anionic selectivities, facilitate the uptake of $\mathrm{SO}_{4}^{2-}$ and $\mathrm{SeO}_{4}^{2-}$ by plant roots, and the complementation of these is genetically determined and may be regulated by the plant's nutritional status.

\section{Application of selenium in fertilizers}

Inorganic Se fertilization on a national scale has proven its efficiency in Finland since 1984, when the interpolation of Se into all multi-element fertilizers became compulsory. Se concentrations in Finnish foodstuffs have since increased dramatically (Ekholm et al., 2007). Soil, climatic, and cropping situations will affect the adequacy of Se biofortification; experiences gained in Finland and other places may not be appropriate to other regions. Another important factor to remark is that the window of Se intake from deficiency to toxicity is rather narrow, necessitating detailed studies on the efficacy of Se biofortification through fertilization if this approach is to be adopted on a commercial 
scale (Broadley et al., 2010).

In controlled environmental studies, growth stimulations induced by $\mathrm{SeO}_{4}^{2-}$ fertilization have been reported in ryegrass (Xue \& Hartikainen, 2000; Cartes et al., 2010), lettuce (Rios et al., 2009), potato (Turakainen et al., 2004), arabidopsis (White et al., 2004), and soybean (Djanaguiraman et al., 2005). Growth or yield stimulation may be because of selenate-induced antioxidant production such as ascorbate and glutathione (GSH) peroxidases that detoxify $\mathrm{H}_{2} \mathrm{O}_{2}$ and improve stress resistance (Ríos et al., 2009). Selenate-induced upregulation of sulphate transport and merger is also likely to happen (Van Hoewyk et al., 2008). Hence, whilst Se is probably beneficial to vascular plants, as to our knowledge, no growth in yield or stress resistance has been observed in Se-enriched field-grown crops (Broadleyet al., 2010).

Different ways of raising Se concentrations have been investigated over the years to overcome the naturally low Se content of crops in some areas, and this subject has been discussed in a number of reviews (Gissel-Nielsen \& Gupta, 2004). It is well known that in Finland in 1984 Se-containing fertilizers came into public use. Sodium selenate is added to the fertilizer slurry in order to obtain an equal Se concentration in the granules during the process of production (Hartikainen, 2005). Since the beginning of Se fertilization, its impact has been regularly monitored by analysing Se in agricultural soils, water and plants, all kinds of feeds, plant and animal foods, and human serum, the results of these works appearing in numerous publications such as Ekholm et al. (1994) or Eurola et al. (2003). The Se amount in fertilizers has been regulated on the basis of these findings. The primary level of $16 \mathrm{mg} \mathrm{kg}^{-1}$ used for cereal crop fertilizers was decreased to $6 \mathrm{mg} \mathrm{kg}^{-1}$ (in 1991). Since this measure had an adverse effect on the crop quality, the Se concentration was increased to the present level of $10 \mathrm{mg} \mathrm{kg}^{-1}$ (in 1998).

Fertilization induced severe changes in the Se concentration of agricultural crops. For instance, in spring cereals, the increase was generally 20-30-fold during the first years of supplementation. The Se amount in 2005 was about 13 times higher than in the mid-1970s. In winter cereals, the Se levels increased at first 2-5-fold to $0.07 \mathrm{mg} \mathrm{kg}^{-1}$ dry weight in 1990 , the present level being about 10-12 times higher than that in the 1970s, as pointed out by Hartikainen (2005).

The first studies on the soil application of Se in the 1960s involved the spraying of selenite or selenate solutions onto the soil surface. These relatively simple experiments from New Zealand and USA showed much promise to increase Se content through such treatments, and they have been followed by extensive studies all over the world (Gissel-Nielsen \& Gupta, 2004). On the 
other hand, a large-scale field experiment involving an annual addition of 60 and $120 \mathrm{~g}$ Se ha ${ }^{-1}$ over a period of 5 years $\left(\right.$ as $\mathrm{Na}_{2} \mathrm{SeO}_{3}$ ) incorporated into a NPK compound fertilizer was carried out in 21 farms covering the common Danish soil types. The soils varied in their content of organic matter, clay, prior cropping, etc. but were all glacial deposit mineral soils with a $\mathrm{pH}$ of $5-7$. The $120 \mathrm{~g}$ Se treatment increased the native Se concentration of $0.02-0.04 \mathrm{mg}$ $\mathrm{kg}^{-1}$ of wheat, barley, rye grass, clover, and fodder beets $\left(0.09 \mathrm{mg} \mathrm{kg}^{-1}\right.$ in the beet top) to $0.08-0.13 \mathrm{mg} \mathrm{Se} \mathrm{kg}^{-1}$, which is considered a sufficient and safe level for animal nutrition (Gissel-Nielsen \& Gupta, 2004). It has been reported that field experiments were carried out on two South Australian sites (Charlick \& Minnipa, 2002), where Se was applied as sodium selenate at rates from 0 to $120 \mathrm{~g} \mathrm{ha}^{-1}$ Se either to the soil upon seeding or as a foliar spray after flowering (Lyons et al., 2005).

Applications of $\mathrm{Na}_{2} \mathrm{SeO}_{3}$ to soils or as a foliage spray are proposed for correcting Se nutritional deficiencies in areas with low soil Se. However, in view of the toxic properties of Se salts, these practices should be carefully controlled and the surplus of Se to soil, at $10 \mathrm{~g} \mathrm{ha}^{-1}$, affected its contents in grains of barley and oat, from 0.019 to $0.26 \mathrm{mg} \mathrm{kg}^{-1}$ and from 0.032 to 0.44

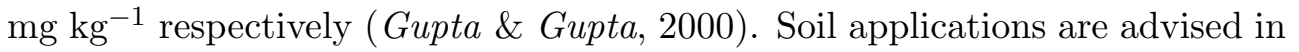
general, particularly for crops bent due to late-season moisture or heat stress (Lyons et al., 2005), although foliar applications can also be efficient (Ducsay \& Ložek, 2006) due to the mobility of Se in plants (Broadley et al., 2010).

\section{Selenium treatment of seeds}

Among the three major methods of Se enrichment, seed treatment has been studied the least. Field experiments have shown that seed treatment with Se offers great promise for enriching soybeans (Glycine max Merr L.), which are rather high accumulators of Se. Recent data has shown that at equivalent rates of seed-applied Se, soybean grain contained higher Se than a number of other feed and food products (Gissel-Nielsen \& Gupta, 2004). The effects of different rates of seed-applied Se for two soybean cultivars have been examined. The results demonstrated that increasing Se from 10 to $100 \mathrm{~g} \mathrm{ha}^{-1}$ proportionately also increased Se concentration in the grain. Thus, grains containing up to 7.5

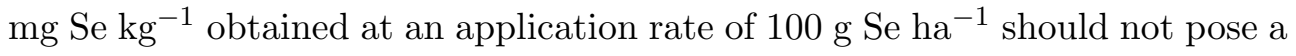
toxicity danger. Due to the higher capacity of soybeans to mobilize Se in the grain, seed treatment with Se offers an alternative for producing crops with the desired Se amounts (Gissel-Nielsen \& Gupta, 2004). Therefore, considering 
all previous experiments, the overall conclusion is that a foliar application of about $5 \mathrm{~g} \mathrm{Se} \mathrm{ha}^{-1}$ as $\mathrm{SeO}_{3}^{2-}$ or $\mathrm{SeO}_{4}^{2-}$, soil fertilization using about $10 \mathrm{~g}$ Se $\mathrm{ha}^{-1}$ as $\mathrm{SeO}_{4}^{2-}$ or about $120 \mathrm{~g} \mathrm{Se} \mathrm{ha}^{-1}$ as $\mathrm{SeO}_{3}^{2-}$, and $10 \mathrm{~g} \mathrm{SeO}_{4}^{2-} \mathrm{Se} \mathrm{ha}^{-1}$ as seed treatment are efficient annual treatments for increasing the Se content of annual crops to a favourable level for human and animal nutrition. The effect of Se is enhanced when it is used with a detersive for foliar application. The greatest impact can be reached when performed on a well-established crop for all treatments. The remaining effect of these treatments is very small and a higher amount is needed for pasture crops, but this gives a residual effect lasting $2-3$ years.

\section{Selenium in edible parts of plants}

Se concentrations in plant foods, such as wheat (Triticum aestivum L.) and rice (Oryza sativa L.), may largely vary among countries and regions. Thus, to avoid Se deficiency and toxicity, it is important to monitor and optimize crop Se concentrations (Zhu et al., 2009). In 2009, a universal survey of Se on rice purchased from retail outlets highlighted that Se levels in main riceproducing and -consuming countries, such as Egypt, China, and Thailand, are low, whereas they were higher in rice produced in the USA and India. The concentration of Se in wheat also shows large regional variations (Hawkesford \& Zhao, 2007). Where both rice and wheat are produced (e.g. India, China and Egypt), the Se concentrations of wheat and rice tend to be similar.

Offsetting regions with inadequate Se by sourcing Se-rich grain is a practical solution to ease the problem, but further characterization of both rice and wheat grain Se concentrations is required (Williams et al., 2009). The Se amount of crops has received much attention recently owing to its importance in the food chain, as mentioned before. Most existing data are related to food and fodder plants. In general, the mean concentrations of Se in grains are higher in countries with dry climates than in countries with humid climates. The average range of mean Se amounts varies from 0.34 to $0.92 \mathrm{mg} \mathrm{kg}^{-1}$ for countries with high Se amounts in grains and from 0.014 to $0.042 \mathrm{mg}$ $\mathrm{kg}^{-1}$ for countries with low Se amounts in grains. These variations do not suggest a significant effect of climatic conditions because several other factors also control the Se absorption by plants (Kabata-Pendias, 2011). It has been found that the environmental trace of the Se concentration in broccoli was about 10 times higher than the genotype impact. A change in the Se uptake by various species of the same plant (Astragalus) is described by Somer and 
Caliskan (2007). It was also found that most plants have rather low Se levels, around $25 \mu \mathrm{g} \mathrm{kg}^{-1}$ and seldom exceed $100 \mu \mathrm{g} \mathrm{kg}^{-1}$. However, some plants show great capability to accumulate Se, and they may concentrate Se to extremely high amounts, which may be toxic to humans and animals. As mentioned before and according to Kabata-Pendias' review in 2011, although Se is not a necessary element for plants, with some exceptions, it is added to soil to ensure that both food and feed crops include enough amounts for dietary needs.

\section{References}

[1] R. L. Mikkelsen, A. L. Page, F. T. Bingham, Factors affecting selenium accumulation by agricultural crops. In: Selenium in agriculture and the environment. Soil Science Society of America \& American Society of Agronomy, Special publication, 23. (1989) 65-94.

[2] A. Shrift, Aspects of selenium metabolism in higher plants. Annual Review of Plant Biology, 20. (1969) 475-494.

[3] L. Wu, Z. Z. Huang, R. G. Burau, Selenium accumulation and selenium-salt co-tolerance in five grass species. Crop Science, 28. (1988) $517-522$.

[4] T. A. Brown, A. Shrift, Selenium: toxicity and tolerance in higher plants. Biological Reviews, 57. (1982) 59-84.

[5] K. Padmaja, D. D. K. Prasad, A. R. K. Prasad, Effect of selenium on chlorophyll biosynthesis in mung bean seedlings. Phytochemistry, 28. (1989) 3321-3324.

[6] M. Aslam, K. B. Harbit, R. C. Huffaker, Comparative effects of selenite and selenate on nitrate assimilation in barley seedlings. Plant, Cell \& Environment, 13. (1990) 773-782.

[7] W. Bosma, R. Svchupp, L. J. De Kok, H. Rennenberg, Effect of selenate on assimilatory sulfate reduction and thiol content in spruce needles. Plant Physiology and Biochemistry, 29. (1991) 131-138.

[8] S. N. Nigam, J. I. Tu, W. B. McConnell, Distribution of selenomethylcysteine and some other amino acids in species of Astragalus, with special reference to their distribution during the growth of A. bisulcatus. Phytochemistry, 8. (1969) 1161-1165. 
[9] N. Terry, A. M. Zayed, M. P. de Souza, A. S. Tarun, Selenium in higher plants. Annual Review of Plant Physiology and Plant Molecular Biology, 51. (2000) 401-432.

[10] C. Reilly, Selenium in food and health. $2^{\text {nd }}$ ed. Springer, Berlin. (2006).

[11] E. Kabata-Pendias, Trace elements in soils and plants. $4^{\text {th }}$ ed. CRC Press, Taylor \& Francis, Boca Raton. (2011).

[12] T. A. Brown, A. Shrift, Selenium: toxicity and tolerance in higher plants. Biological Reviews, 57. (1982) 59-84.

[13] L. F. De Filippis, Biochemical and molecular aspects in phytoremediation of selenium. In: M. Ashraf, M. Ozturk, M. S. A. Ahmad (eds), Plant adaptation and phytoremediation. Springer, Dordrecht/Heidelberg/London/New York. (2010).

[14] E. A. H. Pilon-Smits, Phytoremediation. Annual Review of Plant Biology, 56. (2005) 15-39.

[15] P. J. White, H. C. Bowen, P. Parmaguru, M. Fritz, W. P. Spracklen, R. E. Spiby, M. C. Meacham, A. Mead, M. Harriman, L. J. Trueman, B. M. Smith, B. Thomas, M. R. Broadley, Interactions between selenium and sulphur nutrition in Arabidopsis thaliana. Journal of Experimental Botany, 55. (2004) 1927-1937.

[16] É. Domokos-Szabolcsy, A. Barnóczki, J. Prokisch, A. Sztrik, M. G. Fári, Variation in selenium tolerance among two onion cultivars in closed fortification system. International Journal of Horticultural Science, 17. (2011) 75-77.

[17] M. S. Khan, R. Hell, A future crop biotechnology view of sulfur and selenium. In: J. Joseph (ed.), Sulfur: a missing link between soils, crops, and nutrition, Agronomy monograph. American Society of Agronomy/Crop Science Society of America/Soil Science Society of America, Madison. (2008) 293-311.

[18] N. S. Pasricha, Y. P. Abrol, Food production and plant nutrient sulphur. In: Y. P. Abrol, A. Ahmad (eds), Sulfur in plants. Kluwer Academic Press, Dordrecht. (2003) 29-44.

[19] R. Hell, Molecular physiology of plant sulfur metabolism. Planta, 202. (1997) 138-148. 
[20] T. G. Sors, D. R. Ellis, D. E. Salt, Selenium uptake, translocation, assimilation and metabolic fate in plants. Photosynthesis Research, 86 . (2005b) 373-389.

[21] T. G. Sors, D. R. Ellis, G. N. Na, B. Lahner, S. Lee, T. Leustek, I. J. Pickering, D. E. Salt, Analysis of sulfur and selenium assimilation in Astragalus plants with varying capacities to accumulate selenium. The Plant Journal, 42. (2005a) 785-797.

[22] C. Shennan, D. P. Schachtman, G. R. Cramer, Variation in $\left[{ }^{75}\right.$ Se $]$ selenate uptake and partitioning among tomato cultivars and wild species. New Phytologist, 115. (1990) 523-530.

[23] L. J. Feist, D. R. Parker, Ecotypic variation in selenium accumulation

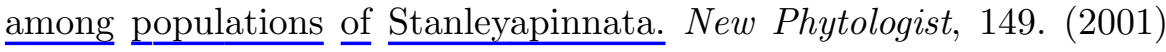
61-69.

[24] A. M. Hurd-Karrer, Selenium absorption by crop plants as related to their sulphur requirement. Journal of Agricultural Research, 54. (1937) 601-608.

[25] P. J. White, H. C. Bowen, B. Marshall, M. R. Broadley, Extraordinarily high leaf selenium to sulfur ratios define 'Se-accumulator' plants. Annals of Botany, 100. (2007) 111-118.

[26] M. J. Hawkesford, Sulphur. In: M. R. Broadley, P. J. White (eds), Plant nutritional genomics. Blackwell, Oxford. (2005) 87-111.

[27] M. M. Abrams, C. Shennan, J. Zazoski, R. G. Burau, Selenomethionine uptake by wheat seedlings. Agronomy Journal, 82. (1990) 1127-1130.

[28] H. Cherest, J. C. Davidian, D. Thomas, V. Benes, W. Ansorge, Y. Surdin-Kerjan, Molecular charecterisation of two high affinity sulphate transporters in Saccharomyces cervisiae. Genetics, 145. (1997) 627-635.

[29] P. Ekholm, H. Reinivuo, P. Mattila, H. Pakkala, J. Koponen, A. Happonen, J. Hellstrom, M. L, Ovaskainen, Changes in the mineral and trace element contents of cereals, fruits and vegetables in Finland. Journal of Food Composition and Analysis, 20. (2007) 487-495.

[30] M. R. Broadley, J. Alcock, J. Alford, P. Cartwright, I. Foot, S. J. Fairweather-Tait, D. J. Hart, R. Hurst, P. Knott, S. P. McGrath, M. 
C. Meacham, K. Norman, H. Mowat, P. Scott, J. L. Stroud, M. Tovey, M. Tucker, P. J. White, S. D. Young, F. J. Zhao, Selenium biofortification of high-yielding winter wheat (Triticumaestivum L.) by liquid or granular Se fertilisation. Plant and Soil, 332. (2010) 5-18.

[31] T. L. Xue, H. Hartikainen, Association of antioxidative enzymes with the synergistic effect of selenium and UV irradiation in enhancing plant growth. Agricultural and Food Science Finl., 9. (2000) 177-186.

[32] P. Cartes, L. Gianfreda, C. Paredes, M. L. Mora, The effect of seed pelletization with selenite on the yield and selenium uptake of ryegrass cultivars. $19^{\text {th }}$ World Congress of Soil Science, Soil Solutions for a Changing World. Brisbane, Australia. Published on CDROM, 1-6. August. (2010) 310-313.

[33] J. J. Ríos, B. Blasco, L. M. Cervilla, M. A. Rosales, E. SanchezRodriguez, L. Romero, J. M. Ruiz, Production and detoxification of $\mathrm{H}_{2} \mathrm{O}_{2}$ in lettuce plants exposed to selenium. Annals of Applied Biology, 154. (2009) 107-116.

[34] M. Turakainen, H. Hartikainen, M. M. Seppänen, Effects of selenium treatments on potato (Solanum tuberosum L.) growth and concentrations of soluble sugars and starch. Journal of Agricultural and Food Chemistry, 52. (2004) 5378-5382.

[35] M. Djanaguiraman, D. D. Devi, A. K. Shanker, A. Sheeba, U. Bangarusamy, Selenium - an antioxidative protectant in soybean during senescence. Plant and Soil, 272. (2005) 77-86.

[36] D. Van Hoewyk, H. Takahashi, E. Inoue, A. T. M. Hess, E. A. H. Pilon-Smits, Transcriptome analyses give insights into selenium-stress responses and selenium tolerance mechanisms in Arabidopsis. Physiologia Plantarum, 132. (2008) 236-253.

[37] G. Gissel-Nielsen, U. C. Gupta, Agronomic approaches to increase selenium concentration and food crops. In: R. M. Welch, I. Âakmak (eds), Impacts of agriculture on human health and nutrition - Encyclopedia of Life Support Systems (EOLSS). (2004). Developed under the Auspices of the UNESCO, Eolss Publishers, Oxford, August, 25. (2012) http://www.eolss.net/Retrieved. 
[38] H. Hartikainen, Biogeochemistry of selenium and its impact on food chain quality and human health. Journal of Trace Elements in Medicine and Biology, 18. (2005) 309-318.

[39] P. Ekholm, M. Ylinen, P. Koivistoinen, P. Varo, Selenium concentration of Finnish foods: effects of reducing the amount of selenate in fertilizers. Agricultural Science Finl., 4. (1994) 377-384.

[40] M. Eurola, G. Alfthan, A. Aro, P. Ekholm, V. Hietaniemi, H. Rainio, R. Rankanen, E. R.Venalainen, Results of the Finnish selenium monitoring program 2000-2001. Agrifood Research Reports 36. MTT Agrifood Research Finland. (2003).

[41] G. H. Lyons, J. C. R. Stangoulis, R. D. Graham, Tolerance of wheat (Triticumaestivum L.) to high soil and solution selenium levels. Plant and Soil, 270. (2005) 179-188.

[42] U. C. Gupta, S. C. Gupta, Selenium in soils and crops, its deficiencies in livestock and humans: implications for management. Communications in Soil Science and Plant Analysis, 31. (2000) 1791-1807.

[43] L. Duscay, O. Ložek, L. Varga, T. Lošák, Wheat supplementation with selenium. Chemistry, 100. (2006) 519-521 (in Slovakian and cited from Kabata-Pendias, 2011).

[44] Y. G. Zhu, E. A. H. Pilon-Smits, F. J. Zhao, P. N. Williams, A. A. Meharg, Selenium in higher plants: understanding mechanisms for biofortification and phytoremediation. Trends in Plant Science, 14. (2009) 436-442.

[45] M. J. Hawkesford, F. J. Zhao, Strategies for increasing the selenium content of wheat. Journal of Cereal Science, 46. (2007) 282-292.

[46] P. N. Williams, E. Lombi, G. X. Sun, K. Scheckel, Y. G. Zhu, X. Feng, J. Zhu, A. M. Carey, E. Adomako, Y. Lawgali, C. Deacon, A. A. Meharg, Selenium characterisation in the global rice supply chain. Environmental Science \& Technology, 43. (2009) 6024-6030.

[47] G. Somer, A. C. Caliskan, Selenium and trace elements distribution in astragalus plants: developing a differential pulse polarographic method for their determination. Turkish Journal of Chemistry, 31. (2007) 411422. 